\title{
RT-LAMP: A Cheaper, Simpler and Faster Alternative for the Detection of SARS-CoV-2 in Wastewater
}

\author{
Isaac Dennis Amoah ${ }^{1}$. Nonsikelelo Precios Mthethwa ${ }^{1} \cdot$ Leanne Pillay $^{1} \cdot$ Nashia Deepnarain ${ }^{1} \cdot$ Kriveshin Pillay $^{1}$. \\ Oluyemi Olatunji Awolusi ${ }^{1} \cdot$ Sheena Kumari ${ }^{1} \cdot$ Faizal Bux $^{1}$ (i)
}

Received: 23 February 2021 / Accepted: 14 July 2021 / Published online: 26 July 2021

(c) The Author(s), under exclusive licence to Springer Science+Business Media, LLC, part of Springer Nature 2021

\begin{abstract}
Reverse transcription loop-mediated isothermal amplification (RT-LAMP) has the potential to become a cheaper and faster option for monitoring COVID-19 infections through wastewater-based epidemiology. However, its application in COVID-19 surveillance has been limited to clinical testing only. We present in this paper two optimized RT-LAMP protocols based on colour change and fluorescence detection and application of these protocols for wastewater monitoring from four wastewater treatment plants over 4 weeks. The optimized RT-LAMP protocols have a limit of detection of 10 copies/25 $\mu$ reaction with positive amplification within 35 minutes. Over the 4 weeks of monitoring, the colorimetric protocol detected a prevalence of $12.5 \%$, when $1 \mu \mathrm{l}$ of extracted RNA with $92.7( \pm 28.2) \mathrm{ng} / \mu$ l concentration was analysed. When the RNA template was increased by fivefold, the prevalence increased to $44 \%$. The fluorescent RT-LAMP had a prevalence of $31 \%$ and $47 \%$ for starting templates of $92.7( \pm 28.2) \mathrm{ng} / \mu \mathrm{l}$ and $480( \pm 134.5) \mathrm{ng} / \mu \mathrm{l}$ of the extracted RNA, respectively. All samples were positive for SARS-CoV-2 when analysed with droplet digital PCR, with viral loads ranging from 18.1 to $195.6 \mathrm{gc} / \mathrm{ml}$ of wastewater. The RT-ddPCR, therefore, confirms the presence of the viral RNA in the wastewater samples, albeit at low concentrations. Additionally, the RT-LAMP protocols positively detected SARS-CoV-2 in wastewater samples with copies as low as 20.7 $\mathrm{gc} / \mathrm{ml}$. The results obtained in our study show the potential application of RT-LAMP for the detection of SARS-CoV-2 in wastewater, which could provide a cheaper and faster alternative to RT-qPCR or RT-ddPCR for wastewater-based epidemiological monitoring of COVID-19 and other viral infections.
\end{abstract}

Keywords Loop-mediated isothermal amplification · LAMP · SARS-CoV-2 · COVID-19 · Wastewater-based epidemiology $\cdot$ Surveillance

\section{Introduction}

Wastewater-based epidemiology (WBE) has become a very popular tool for monitoring COVID-19 infections. This is not a new approach; however, its relevance has increased due to challenges with traditional disease surveillance approaches. The principle of wastewater-based surveillance was first applied for environmental surveillance of polio in the late 1980s in Israel (Hovi et al., 2012), although the term WBE was theorized in 2001 by Daughton and JonesLepp (2001). Since then, the WBE approach has been used

Faizal Bux

faizalb@dut.ac.za

1 Institute for Water and Wastewater Technology, Durban University of Technology, P.O. Box 1334, Durban 4000, South Africa extensively in monitoring cocaine consumption (Mao et al., 2020; Tang et al., 2020; Zuccato et al., 2005), pharmaceutical consumption (Baz-Lomba et al., 2016; He et al., 2020), viral infections (Hou et al., 2020) and infections with antibiotic-resistant bacteria (Castrignanò et al., 2020; Hutinel et al., 2019). During the current COVID-19 pandemic, WBE has been used extensively in several countries to monitor SARS-CoV-2 infections (Ahmed et al., 2020; Kumar et al., 2020; La Rosa et al., 2020; Lodder \& de Roda Husman, 2020; Medema et al., 2020; Randazzo et al., 2020; Rimoldi et al., 2020; Wu et al., 2020a, b; Wurtzer et al., 2020). The use of WBE for monitoring COVID-19 infections provides several advantages, including a better resolution of infections within communities due to shedding of the virus by both symptomatic and asymptomatic patients (Lee et al., 2020; Li et al., 2020; Sohn et al., 2020). Furthermore, WBE provides a quick turn-around time from sampling to results, 
and it is scalable and cost effective even in low-resource settings compared to COVID-19 surveillance via clinical testing (Hart \& Halden, 2020).

Despite the numerous benefits of WBE, the main limitation of this approach is the reliance on the same testing platforms used for clinical testing. Most of the reports of WBE so far rely on the reverse transcription quantitative polymerase chain reaction (RT-qPCR) technique, which is the same method used for clinical testing. This presents a major challenge due to the limited access to RT-qPCR consumables that most laboratories experienced during the initial pandemic peaks. It is, therefore, imperative to find alternative testing methodologies or platforms. In addition to providing an option that does not rely on the same consumables used during clinical testing, these methods should be much cheaper to allow for widespread adoption. One such candidate is the loop-mediated isothermal amplification (LAMP). In this method, the nucleic acid is amplified under isothermal conditions, eliminating the need for thermal cyclers (Obande \& Singh, 2020). This method is reported to be efficient, fast and highly specific due to the use of six independent primers (Mukama et al., 2020). Reverse transcription LAMP (RT-LAMP) protocols have been developed for the detection of a variety of viruses (Wong et al., 2018). This has facilitated the rapid detection of infections with COVID-19 (Lamb et al., 2020; Park et al., 2020; Yu et al., 2020). However, to date, the use of RT-LAMP for WBE is limited. We, therefore, present the optimization of RT-LAMP for WBE monitoring of COVID-19 based on detection of the SARS$\mathrm{CoV}-2$ in wastewater. We believe that this approach has the potential to substantially reduce the costs and time required for WBE and will be a valuable tool in the surveillance of COVID-19 as well as other similar infections in the future.

\section{Methodology}

\section{Optimization of RT-LAMP for Detection of SARS-CoV-2 RNA}

Optimization of the RT-LAMP method was performed using synthetic SARS-CoV-2 RNA purchased from Exact Diagnostics (Texas, USA). This contained 10, $000 \mathrm{gc} / \mu \mathrm{l}$ each of five (5) gene targets (E, N, ORF1ab, RdRP and S). To determine the limit of detection (LOD) of the RT-LAMP approach, we diluted the synthetic RNA serially to achieve presumptive concentrations of 1000,100, 10 and 1 copy per $\mu \mathrm{l}$. These were added to the $25 \mu \mathrm{l}$ reaction volume to determine the LOD, corresponding to SARS-CoV-2 RNA concentrations of 400, 40, 4, 0.4 and 0.04 copies per $\mu$ lof the reaction volume. Two RT-LAMP methods were applied in this study. The first approach was the colorimetric or visual RT-LAMP technique, which allows for visual reading of the results, while the second approach used was the Fluorescent RT-LAMP that uses a fluorescent dye to assist with the detection of positive amplification. Irrespective of the RTLAMP approach used, the reaction was carried out at $65^{\circ} \mathrm{C}$ (using a heating block) and a reaction time of 35 minutes, as determined during the optimization stage. The LAMP primers used for both colorimetric and Fluorescent RT-LAMP techniques were taken from Huang et al., 2020. These primers target the nucleocapsid protein of the SARS-CoV-2 genome ( $\mathrm{N}$ gene). The details of these two approaches (colorimetric and Fluorescent RT-LAMP) are presented in the sections below.

\section{Colorimetric/Visual LAMP Method (Phenol Red Indicator)}

The colorimetric RT-LAMP reaction mix consisted of $12.5 \mu \mathrm{l}$ WarmStart Colorimetric LAMP 2X Master Mix (WarmStart isothermal amplification buffer, Bst 2.0 WarmStart DNA/RNA Polymerase, RTx Reverse Transcriptase) (New England Biolab, USA), Phenol red indicator (for visual colour), LAMP Primer Mix (10X) $(2 \mu \mathrm{M}$ F3 primer, $2 \mu \mathrm{M}$ B3 primer, $16 \mu \mathrm{M}$ FIP, $16 \mu \mathrm{M}$ BIP, $8 \mu \mathrm{M}$ LoopF and $8 \mu \mathrm{M}$ LoopB), $1 \mu$ template RNA, extracted as described below, and PCR-grade water. The phenol red indicator allows for clear visual detection of amplification which is based on the production of protons and decreases in $\mathrm{pH}$ that occurs as a result of extensive RNA polymerase activity in a LAMP reaction, producing a change in colour from red/pink to yellow. The results were observed instantly upon removal of reaction from the heating block and recorded. During the optimization stage, where the LOD was measured using the synthetic SARS-CoV-2 RNA, results were taken every 5 minutes to determine the minimum time required for a positive reaction to occur. The initial results were also confirmed by gel electrophoresis (Figs. S1 and S2).

\section{Fluorescent RT-LAMP (Fluorescent Dye)}

The $25 \mu \mathrm{l}$ reaction mix for the fluorescent RT-LAMP method utilized the $12.5 \mu \mathrm{l}$ WarmStart amplification kit which contained the same reaction mix components as described in the colorimetric/visual LAMP method section above. The only difference was the replacement of the phenol red indicator with 50X SYBR green (fluorescent dye), which binds to dsDNA for real-time detection of LAMP. The fluorescent RT-LAMP was performed in a CFX96 Touch Deep Well Real-Time thermal cycler (Bio-rad, USA) to enable the measurement of the fluorescence during amplification. The fluorescent intensity was measured each minute and the time taken for a reaction (sample) to cross the cycle 
threshold was recorded to determine the time taken for positive amplification.

\section{Application of Optimized RT-LAMP for Detection of SARS-CoV-2 in Wastewater Samples}

To test the suitability of the optimized RT-LAMP methods for WBE of COVID-19, untreated wastewater samples were taken from four (4) wastewater treatment plants (WWTPs) in the province of KwaZulu-Natal, South Africa. These WWTPs are Isipingo and Central in Durban and Darvill and Howick in Pietermaritzburg. These samples were taken on a weekly basis for a period of four (4) weeks. Grab samples of approximately 2 litres were collected at the head of works of each plant in the mornings during the peak flow and brought to the laboratory for analysis. In the laboratory, samples were pasteurized at $60{ }^{\circ} \mathrm{C}$ for 90 minutes and $250 \mathrm{ml}$ measured for further processing after cooling to room temperature. The viral particles in the samples were concentrated by centrifugal ultrafiltration using the Centricon Plus-70 ultrafilter (Merck, Germany) as described by Medema et al. (2020). The concentrated samples were then aliquoted $(140 \mu \mathrm{l})$ for RNA extraction using the QiAmp Viral RNA MiniKit (Qiagen, Hilden, Germany), according to manufacturer's instructions. The quality and quantity of the extracted RNA were assessed using the Implen Nanophotometer®. The presence of SARS-CoV-2 in the extracted RNA was then determined using the RT-LAMP protocols described above. Additionally, the samples were analysed with RT-ddPCR to confirm and compare the results obtained with RT-LAMP.

\section{Detection and Quantification of SARS-CoV-2 Using Droplet Digital PCR}

Droplet digital PCR detection of SARS-CoV-2 in the extracted RNA was performed using a one-step RT-ddPCR Advanced Kit for Probes supplied by Bio-rad (USA). The primers and probes targeting the N1 region of the viral genome were used (CDC, 2020). A $22 \mu \mathrm{l}$ reaction mixture was prepared containing, $5 \mu \mathrm{l}$ of supermix, $2 \mu \mathrm{l}$ of reverse transcriptase, $1 \mu \mathrm{l}$ of dithiothreitol, $1.98 \mu \mathrm{l}$ each of the forward and reverse primers $(10 \mu \mathrm{M}), 0.55 \mu \mathrm{l}$ of the $10 \mu \mathrm{M}$ probes, $2.4910 \mu \mathrm{M}$ of PCR-grade water and $7 \mu \mathrm{l}$ of the extracted RNA. Droplets were generated using an automated droplet generator (QXDx Automated Droplet Generator, Bio-rad, USA). The thermal cycling conditions were reverse transcription at $50{ }^{\circ} \mathrm{C}$ for $1 \mathrm{~h}$, followed by enzyme activation at $95{ }^{\circ} \mathrm{C}$ for 10 minutes and 40 cycles of denaturation at $94{ }^{\circ} \mathrm{C}$ for $30 \mathrm{~s}$ and $60 \mathrm{~s}$ of annealing at $55{ }^{\circ} \mathrm{C}$. Enzyme deactivation was performed at $98{ }^{\circ} \mathrm{C}$ for 10 minutes and the droplets stabilized at $4{ }^{\circ} \mathrm{C}$ for 30 minutes with a ramp rate of $2{ }^{\circ} \mathrm{C} / \mathrm{s}$. The QX200 Droplet Reader was used in reading the results after thermal cycling, with QuantaSoft 1.7 software (Bio-rad, USA), and data analysed using the QuantaSoft Analysis Pro 1.0 software (Bio-rad, USA).

The quality control for the RT-ddPCR method used in this study involved the addition of positive, negative, and notemplate controls to each plate/run during the amplification step. The positive controls were synthetic RNA targeting the five regions (E, N, ORF1ab, RdRP, and S genes) of the SARS-CoV-2 viral genome. Negative controls were human genomic DNA and RNA, and sterile nuclease-free water was used as the no-template controls. The negative and positive controls were purchased from Exact Diagnostics (USA). The efficiency of the concentration and extraction methods was assessed by first seeding $400 \mathrm{ml}$ of raw wastewater with a $200 \mu \mathrm{l}$ suspension (corresponding to 3360 copies of $\mathrm{N} 2$ gene) of inactivated SARS-CoV-2 strain USA/WA1/2020 (Microbiologics, USA). This was mixed thoroughly and thereafter separated into $8 \times 50 \mathrm{ml}$ centrifuge tubes (each containing approximately 420 copies of $\mathrm{N} 2$ gene) and processed according to the protocols described above. Unseeded wastewater was also assessed to determine the presence of background concentrations of SARS-CoV-2. The possible effect of inhibitors was also evaluated in the same manner by spiking $120 \mathrm{ml}$ of sterile Milli-Q water with $60 \mu \mathrm{l}$ of inactivated SARS-CoV-2 and processing it under the same conditions. The recovery efficiency of both the wastewater and Milli-Q water was calculated using the following equation:

Recovery $\%=\frac{C_{\mathrm{sw}}-C_{\mathrm{uw}}}{C_{\mathrm{sc}}} \times 100$,

where $C_{\mathrm{SW}}$ is the concentration of SARS-CoV-2 detected in spiked wastewater or Milli-Q water, $C_{\mathrm{UW}}$ is the concentration of SARS-CoV-2 detected in un-spiked wastewater or Milli-Q water and $C_{\mathrm{SC}}$ is the concentration of SARS-CoV-2 that was spiked into the wastewater or Milli-Q water. Taking into consideration that $60 \mathrm{ml}$ of a spiked sample contains 504 copies of $\mathrm{N} 2$, the recovery percentage for wastewater was determined to be at $62.90( \pm 12.8) \%$ for wastewater and $78.62( \pm 1.79) \%$ for Milli-Q water. The differences in the recovery efficiency of wastewater and Milli-Q water may be due to the presence of inhibitors in the wastewater. The methods to determine recovery efficiency were carried out in triplicates. The concentration of SARS-CoV-2 reported, therefore, accounted for the recovery efficiencies mentioned above. 


\section{Results}

\section{Optimization and Determination of Limit of Detection with Synthetic RNA}

The colorimetric RT-LAMP protocol successfully amplified the synthetic SARS-CoV-2 RNA in all the 10,000 and 1000 $\mathrm{gc} / 25 \mu \mathrm{l}$ reactions $(100 \%)$. The efficiency thereafter reduced, amplifying in $66.6 \%$ of the 100 and $10 \mathrm{gc} / 25 \mu \mathrm{l}$ reactions (two out of the three samples analysed showed positive amplification). This was further reduced to $33 \%$ (one out of three samples analysed had positive amplification) when the RNA concentrations were reduced to $1 \mathrm{gc} / 25 \mu \mathrm{l}$ reaction and no amplification in the no-template controls (NTC). The time taken for a positive colour change (from red/pink to yellow) varied depending on the concentration of the SARSCoV-2 RNA analysed. It took a minimum of 25 minutes for positive amplification in all the reactions for the 10,000 and $1000 \mathrm{gc} / 25 \mu \mathrm{l}$ reactions. Thereafter, the time taken for positive reaction increased to 30 minutes for the $100 \mathrm{gc} / 25 \mu \mathrm{l}$ reactions and 35 minutes for the rest of the SARS-CoV-2 concentrations (Table 1).

Comparatively, similar results were obtained with the fluorescent RT-LAMP approach. There was positive amplification in all the concentrations except for the 1 $\mathrm{gc} / 25 \mu \mathrm{l}$ reaction. However, the time taken for the fluorescent intensity to cross the threshold, indicating a positive amplification, was shorter compared to the time required for positive amplification using the colorimetric approach. For instance, it took 14 minutes for the $10,000 \mathrm{gc} / 25 \mu \mathrm{l}$ reaction to cross the threshold (Fig. 1). In addition, the rest of the concentrations produces fluorescent crossing
Table 1 Limit of detection for RT-LAMP using the colorimetric method

\begin{tabular}{lllllll}
\hline RNA copies/reaction* & 10,000 & 1000 & 100 & 10 & 1 & NTC \\
\hline Number of positive reactions & $3 / 3$ & $3 / 3$ & $2 / 3$ & $2 / 3$ & $1 / 3$ & 0 \\
Time for positive reaction & $25 \mathrm{~min}$ & $25 \mathrm{~min}$ & $30 \mathrm{~min}$ & $35 \mathrm{~min}$ & $35 \mathrm{~min}$ & N/A \\
\hline
\end{tabular}

*Copies calculated based on copy numbers stated by supplier (Exact Diagnostics), the reaction volume was $25 \mu \mathrm{l}$

\section{Amplification Plot}

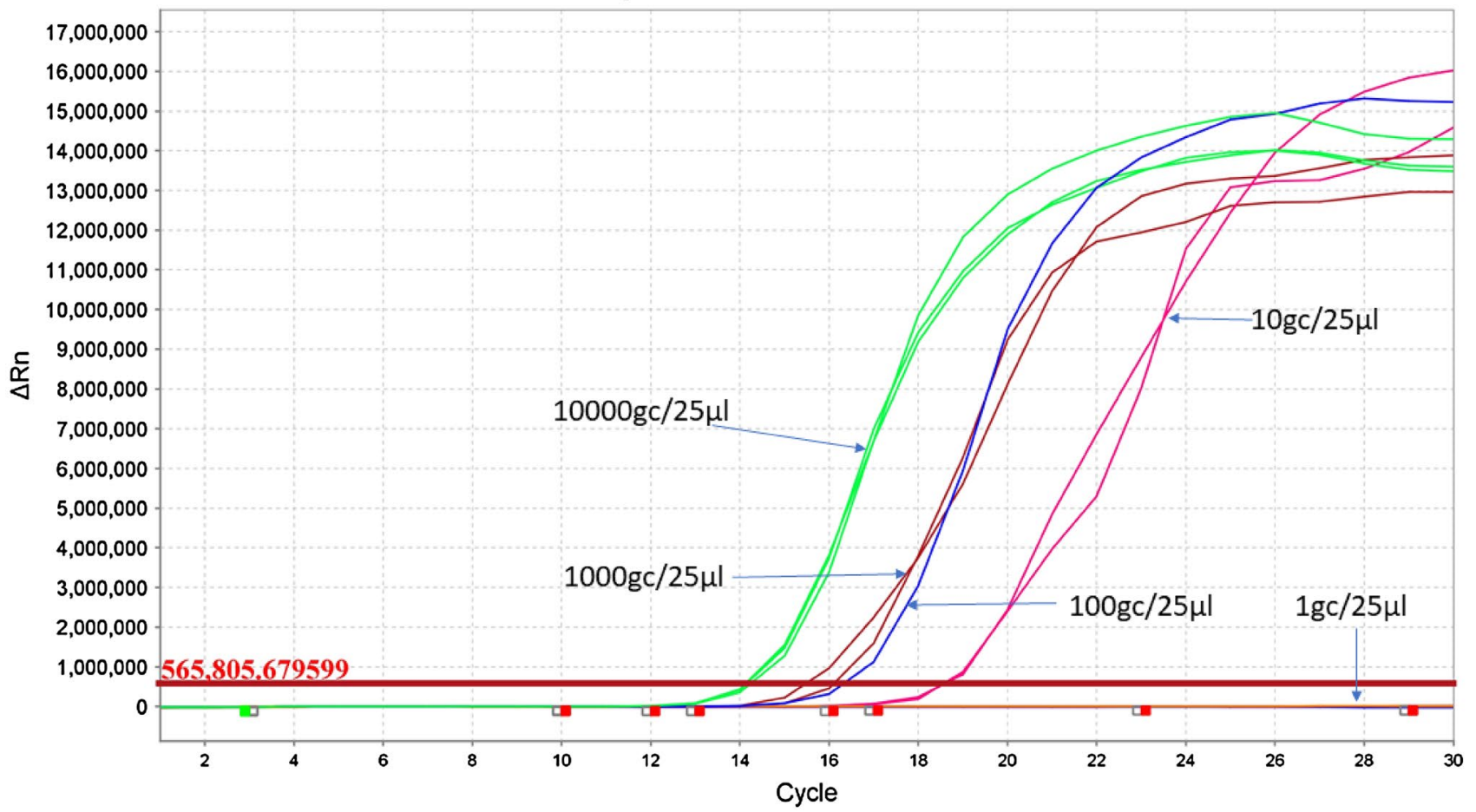

Fig. 1 Amplification plot of the limit of detection assessment using the fluorescent approach 
the threshold before 20 minutes, except the $1 \mathrm{gc} / 25 \mu \mathrm{reac}-$ tion which did not cross the threshold as shown in Fig. 1.

To check the specificity of the RT-LAMP assay for the detection of SARS-CoV-2, a melt curve was plotted using the different concentrations of the synthetic RNA. This plot as presented in the supplementary information (Fig. S3) showed a typical curve of a specific PCR assay with a melting temperature of $90^{\circ} \mathrm{C}$.

\section{Application of the RT-LAMP in the Detection of SARS-CoV-2 in Wastewater}

The concentration of extracted RNA from each wastewater sample varied from $62.7( \pm 0.9)$ to $152( \pm 4.8) \mathrm{ng} /$ $\mu \mathrm{l}$ (Table 2). The colorimetric RT-LAMP protocol was successful in detecting SARS-CoV-2 in $12.5 \%(2 / 16)$ of the wastewater samples analysed when $1 \mu \mathrm{l}$ of starting template was used. Only samples taken from Darvill WWTP, during weeks 1 and 4 had positive amplification (Fig. S4). The concentration of extracted RNA in these positive samples was 76.1 $( \pm 0.8) \mathrm{ng} / \mu \mathrm{l}$ and $66.3( \pm 2.3)$ $\mathrm{ng} / \mu \mathrm{l}$, respectively (Table 2). Samples taken from Central WWTP in week 2 showed a faint colour change in one of the two tubes (this was not very clear) and was, therefore, considered as a negative sample to avoid false-positive results. To increase the template RNA in each reaction, the volume of extracted RNA was increased to $5 \mu \mathrm{l}$ for all samples. This resulted in an increase in the prevalence of positive samples. For instance, approximately, $44 \%$ of the wastewater samples analysed were positive for SARSCoV-2 when the starting RNA template was increased to $5 \mu \mathrm{l}$ (Table 2; Fig. S4). Three (3) (Weeks 1, 2 and 4) out of the four (4) wastewater samples from Central WWTP were positive and it is worth noting that the same sample (Week 2) which produced a faint colour change when $1 \mu$ RNA was used, was now a strong positive. In Darvill WWTP, an additional positive amplification was recorded in Week 3 , as well as those positive samples when $1 \mu \mathrm{l}$ starting template was used (Weeks 1 and 4). Although no positive amplification was recorded in Isipingo WWTP when $1 \mu \mathrm{l}$ RNA template was used, increasing the template to $5 \mu \mathrm{l}$ resulted in a positive detection in Week 4 (Table 2; Fig. S4).

The fluorescent RT-LAMP was more sensitive for detecting SARS-CoV-2 in the wastewater samples than the colorimetric approach. For instance, using a $1 \mu \mathrm{l}$ RNA template, $31 \%$ of the wastewater samples were positive (Fig. $\mathrm{S} 4 \mathrm{~A}$ ), compared to the $12.5 \%$ obtained with the colorimetric RT-LAMP protocol. Increasing the starting RNA template to $5 \mu \mathrm{l}$ increased the prevalence to $47 \%$ using RT-LAMP (Table 2; Fig. S5B). This shows an improved detection with increasing RNA template in the samples using both calorimetric and RT-LAMP method. It is worth noting that

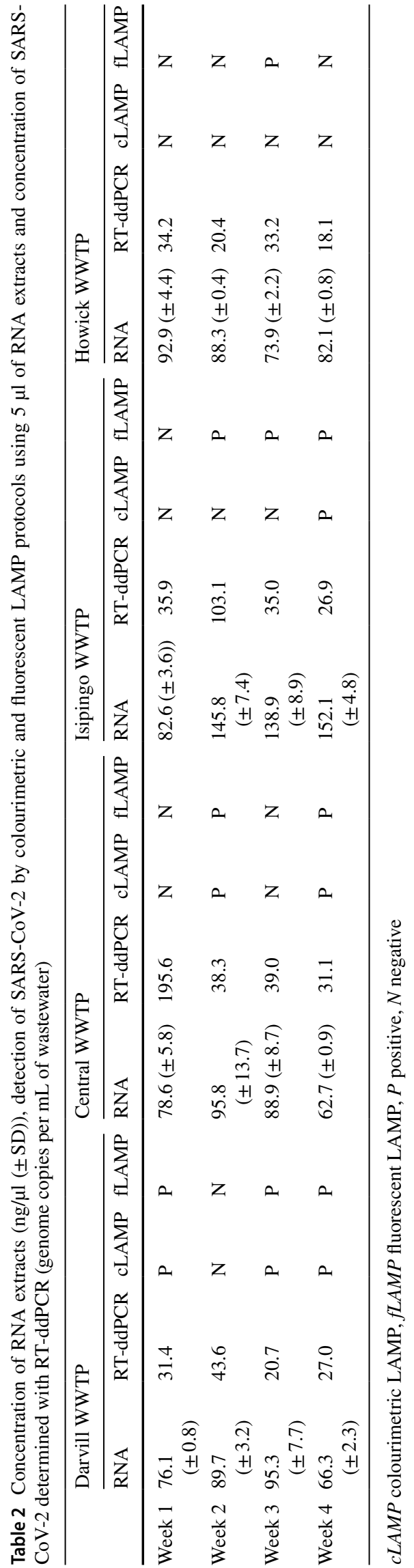


there was an observed difference in the samples that were positive when different starting template volume was used. For instance, in Central WWTP using $1 \mu$ of RNA, Week 3 samples were positive, however, increasing the starting template to $5 \mu$ resulted in Weeks 2 and 4 samples being positive. Similar disparities were observed in samples from most of the other sampling sites (Fig. S5). However, the results show that increasing the RNA template (based on increasing volumes) could improve the sensitivity of the RTLAMP method when the concentration of the target in the samples is low.

\section{Confirmation of SARS-CoV-2 in Wastewater Using Droplet Digital PCR}

Droplet digital PCR detected SARS-CoV-2 in all samples (100\% prevalence), however, the concentrations varied. The concentration of the viral RNA varied from 18.1 to 195.6 $\mathrm{gc} / \mathrm{ml}$ of wastewater, with Central WWTP samples taken at Week 1 giving the highest concentration (Table 2). It is worth noting that despite a high SARS-CoV-2 concentration in Week 1, as measured by RT-ddPCR, none of the RTLAMP protocols (colorimetric or fluorescent) were able to detect SARS-CoV-2. However, the fluorescent RT-LAMP protocol using both $1 \mu \mathrm{l}$ and $5 \mu \mathrm{l}$ RNA extract gave positive amplification when the sample with the second highest SARS-CoV-2 concentration $(103.1 \mathrm{gc} / \mathrm{ml}$ of wastewater from Isipingo WWTP) was analysed.

\section{Discussion}

The RT-LAMP protocols developed in this study successfully amplified SARS-CoV-2 in synthetic RNA, with LOD down to 10 copies per $25 \mu \mathrm{l}$ reaction $(0.4$ copies $/ \mu$ reaction volume). One of the key fundamental principles for disease monitoring is the speed within which results become available, excluding sample processing the protocols presented in this study were able to produce results within 35 minutes. The LOD determined with the synthetic RNA in our study indicated a more sensitive approach compared to an LOD of 118.6 copies $/ 25 \mu$ reported by Lu et al. (2020a, b), However, Huang et al. (2020) reported a more sensitive protocol with LOD of 2 copies $/ 25 \mu$ l. However, it must be noted that these studies focused on RT-LAMP development for clinical diagnosis of COVID-19. Although the LODs were the same between the colorimetric and fluorescent RT-LAMP protocols, the time taken for positive amplification was shorter with the latter. This could be attributed to the difference in the principle of these two protocols. The colorimetric RTLAMP is dependent on the production of enough proton ions to cause a change in $\mathrm{pH}$ necessary for colour change. The initial $\mathrm{pH}$ of the reaction mix could, therefore, potentially affect the time for colour change. Huang et al. (2020) stated that the elution buffer used during the nucleic acid extraction step could significantly affect the results. On the other hand, the shorter time required for positive amplification with the fluorescent RT-LAMP method could be due to the intercalating activity of the fluorescent dyes (SYBR green) used with this method.

The detection of SARS-CoV-2 in the wastewater samples varied greatly between the two RT-LAMP protocols. For instance, the colorimetric approach had a prevalence of $12.5 \%$ compared to the $31 \%$ measured with the fluorescent RT-LAMP. This could be due to the reasons given above $(\mathrm{pH})$, as well as the potential impact of inhibitors (present in wastewater) that may also affect the colour change. For instance, Nixon et al. (2014) reported that urea, a known PCR inhibitor, delays positive amplification with LAMP, although the limit of detection was not affected. Jevtuševskaja et al. (2017) also observed that the inhibitory impact of urine during LAMP reaction is due to the presence of salts. Increasing the starting template produced similar results with both the colorimetric and fluorescent RTLAMP approaches (Supplementary material; Figs. S4 and S5), although the latter had higher prevalence. The improved detection of SARS-CoV-2 by both techniques with increase in template volume could be attributed to an increase in the concentration of SARS-CoV-2. Previous studies by $\mathrm{Lu}$ et al. (2020a, b) observed that by increasing the concentration of the target nucleic acid, exceeding the LOD, the time for positive amplification reduces, this was observed in our study as well (Fig. S5). The RT-ddPCR results provides an opportunity to ascertain the absolute concentration of SARS-CoV-2 in the samples analysed and confirm the results obtained with RT-LAMP. Although the prevalence determined by RT-ddPCR was higher (100\%) compared to the two RT-LAMP approaches, it is worth noting that the concentration of SARS-CoV-2 per ml of wastewater was low. The RT-ddPCR technique has been reported to have a lower limit of detection, higher sensitivity, less influenced by PCR inhibitors and higher accuracy compared to RT-qPCR, for the detection of SARS-CoV-2 (Dong et al., 2021; Falzone et al., 2020; Liu et al., 2020; Lu et al., 2020a, b; Vasudevan et al., 2021). This could account for the higher prevalence of the virus in wastewater using the RT-ddPCR assay. Only two samples (Central Week 1 and Isipingo Week 2) had SARSCoV- 2 copies per $\mu \mathrm{l}$ exceeding the 10 copies $/ 25 \mu \mathrm{LOD}$ for the RT-LAMP protocols. Therefore, the lower prevalence measured with these RT-LAMP protocols could be attributed to lower copies of the viral target in the extracted RNA. It was also observed that, both RT-LAMP protocols gave positive amplification in samples where SARS-CoV-2 copies were below 10 copies per $25 \mu \mathrm{l}$, based on the RT-ddPCR results. This indicates that RT-LAMP could potentially detect lower copies of the viral RNA. For instance, based 
on the RT-LAMP results, SARS-CoV-2 concentrations in week 4 wastewater samples from Darvill, Isipingo and Central WWTPs were 5.1 copies/ $\mu 1,5.0$ copies/ $\mu$ l and 5.8 copies/ $\mu \mathrm{l}$, respectively, corresponding to $27.0 \mathrm{gc} / \mathrm{ml}, 26.9 \mathrm{gc} / \mathrm{ml}$ and $31.1 \mathrm{gc} / \mathrm{ml}$ of wastewater, respectively, and RT-LAMP had positive results for these samples. Interestingly, samples with high copies of the viral RNA per the RT-ddPCR results, such as the week 1 samples from Central WWTP (36.7 copies/ $\mu$ l corresponding to $195.6 \mathrm{gc} / \mathrm{ml}$ of wastewater) had a faint colour change with the $5 \mu \mathrm{l}$ RNA template. This shows inconsistency in the RT-LAMP approach, attributable to inhibitors as mentioned earlier, although LAMP has been reported to be less affected by inhibitors.

Despite the limitations associated with inhibitors, the RTLAMP protocols presented in this study have the potential for application in different locations. Varying concentrations of SARS-CoV-2 have been reported in the literature, with some concentrations higher than the measurements in this study and others lower. For instance, Sherchan et al. (2020) reported concentrations between 3.1 and 4.3 copies/ $\mathrm{ml}$ in Louisiana, USA, which is lower than the concentrations recorded in this study. However, similar or higher concentrations have been reported by Haramoto et al. (2020), Miyani et al. (2020) and Wu et al. (2020a, b). These results, therefore, show that RT-LAMP could potentially be adopted for the detection of SARS-CoV-2 in wastewater, due to viral concentrations higher than the LOD. Therefore, with further research and optimization, RT-LAMP can be a good alternative for WBE.

\section{Implication of Findings for Monitoring of COVID-19 Through Wastewater-Based Epidemiology}

The current methods used for amplifying SARS-CoV-2 RNA for WBE monitoring of COVID-19 are RT-qPCR (Ahmed et al., 2020; Medema et al., 2020; Wurtzer et al., 2020) and to a lesser extent RT-ddPCR (Graham et al., 2020). These techniques despite being effective are expensive and time consuming, and requires skilled personnel. The RT-LAMP approach presented in this study presents a much better alternative. The RT-LAMP is useful in

1. Cost saving: The main instrument required for RTLAMP is a heating block or water bath that can provide a stable temperature $\left(65^{\circ} \mathrm{C}\right.$ in this case $)$ for amplification when using the colorimetric RT-LAMP protocol. These are equipment that are readily available in most laboratories; therefore, RT-LAMP does not come with an additional cost. The cost of the RT-LAMP in relation to equipment required may be similar to that of RTqPCR if the fluorescent RT-LAMP protocol is adopted. However, based on the results recorded in our study, the colorimetric approach could be used effectively in instances where the concentration of the SARS-CoV-2 in the samples is expected to be high due to high number of infected people within the catchment/community and the RNA extraction procedure ensures inhibitor removal (based on quality assessment). Additionally, the LAMP reagents are also reported to more stable and can be stored at $25{ }^{\circ} \mathrm{C}$ or $37^{\circ} \mathrm{C}$ (Thekisoe et al., 2009), therefore, does not require cold storage facilities. This makes it (RT-LAMP) possible to be used in resourceconstrained settings as well.

2. Time: The time required for results with normal qPCR protocols for detection of SARS-CoV-2 exceed an hour; however, the protocols proposed in this study provides results in a maximum of 35 minutes. This ensures that data are produced within a short time, a feature that is very critical for decision making in relation to infection monitoring. Coupled with the fact that WBE is touted as an early warning system for COVID-19, the use of RT-LAMP could be very instrumental in providing a quick turn-around time for results and implementation of interventions. Additionally, the shorter time required for analysis with RT-LAMP means that more samples can be analysed and saves on running expenses (mainly electricity costs and human resources) for the laboratory.

\section{Limitations with the Use of RT-LAMP for Wastewater-Based Epidemiology}

Despite the advantages and the promising nature of the results presented in this paper, there are a few limitations with the RT-LAMP approach that needs to be addressed to enhance its suitability for WBE.

1. Quantification: The main challenge with the current RT-LAMP approach is that it is a qualitative molecular analysis tool with no quantification. Therefore, its applicability is limited to detection of the presence of SARS$\mathrm{CoV}-2$ but cannot provide information on the viral load. The viral load determination is important if one is interested in determining the shedding rates in stool of infected people, copy numbers per volume of wastewater, number of people infected or observing the changes in infection numbers. However, as an early warning system RT-LAMP is perfect as it provides information on the presence of the SARS-CoV-2 in wastewater, which indicates infection in the catchment.

2. Limit of detection: Despite a good limit of detection as compared to other publications on the application of RT-LAMP in clinical diagnostics, the low prevalence recorded compared to RT-ddPCR could be a limitation. In areas where the infection numbers are low, the 10 copies/25 $\mu$ ldetection limit could be a limitation. There- 
fore, further work could focus on improving the limit of detection so as to improve its suitability for WBE. However, an alternative for now will be to increase the volume of the starting RNA template. For instance, as observed in this study increasing the starting template from 1 to $5 \mu \mathrm{l}$, which increased the RNA template, improved the detection significantly.

3. Impact of inhibitors: Some inconsistencies in the RTLAMP results were observed, this could mainly be due to the impact of amplification inhibitors in the RNA extracts. This, therefore, calls for further studies to further improve the accuracy of RT-LAMP.

\section{General Conclusions and Recommendation}

RT-LAMP is a powerful tool that can address the cost and time challenge associated with WBE. In this study, we demonstrated the successful application of RT-LAMP (both colorimetric and fluorescent) in detecting SARSCoV-2 in wastewater over a 4-week period. This approach could produce results in less than an hour and has a LOD of 10 copies $/ 25 \mu \mathrm{l}$. Starting with a high volume of extracted RNA improved the detection which could also ensure elimination of false negatives. However, there is the need for further method development and optimization to ensure consistency in the results.

Despite the challenges of the RT-LAMP as elaborated above, we recommend the use of this approach as a quick molecular analysis tool to determine COVID-19 infections within the catchment areas of WWTPs. This approach could be adapted for future outbreaks, to provide a quicker, cheaper and less-complicated tool for monitoring infections via wastewater-based epidemiology.

Supplementary Information The online version contains supplementary material available at https://doi.org/10.1007/s12560-021-09489-7.

Acknowledgements We are grateful to the Institute for Water and Wastewater Technology (IWWT) of the Durban University of Technology (DUT) and Umgeni water for funding this work. The financial support of the South African Research Chair Initiative (SARChI) of the National Research Foundation and the Department of Science and Technology is also acknowledged. We are also grateful for the support of the operators of the wastewater treatment plants for allowing us sample from their plants.

Author Contributions All authors were involved in the conceptualization of the study and IDA, LP, and NPM performed data collection. The first draft of the manuscript was prepared by IDA and LP. Final review and approval of the manuscript was done.

Funding This work was funded by Umgeni water, National Research Foundation of South Africa (NRF-ZA) and the Durban University of Technology.
Data Availability All data generated during this study are in the manuscript.

\section{Declarations}

Conflict of interest The authors have no conflict of interest to declare.

\section{References}

Ahmed, W., Angel, N., Edson, J., Bibby, K., Bivins, A., O’Brien, J. W., Choi, P. M., Kitajima, M., Simpson, S. L., Li, J., \& Tscharke, B. (2020). First confirmed detection of SARS-CoV-2 in untreated wastewater in Australia: A proof of concept for the wastewater surveillance of COVID-19 in the community. Science of the Total Environment, 728(1), 138764.

Baz-Lomba, J. A., Salvatore, S., Gracia-Lor, E., Bade, R., Castiglioni, S., Castrignanò, E., Causanilles, A., Hernandez, F., KasprzykHordern, B., Kinyua, J., \& McCall, A. K. (2016). Comparison of pharmaceutical, illicit drug, alcohol, nicotine and caffeine levels in wastewater with sale, seizure and consumption data for 8 European cities. BMC Public Health, 16(1), 1-11.

Castrignanò, E., Kannan, A. M., Proctor, K., Petrie, B., Hodgen, S., Feil, E. J., Lewis, S. E., Lopardo, L., Camacho-Muñoz, D., Rice, J., \& Cartwright, N. (2020). (Fluoro) quinolones and quinolone resistance genes in the aquatic environment: A river catchment perspective. Water Research, 182(1), 116015.

Centers for Disease Control and Prevention. (2020). 2019-Novel coronavirus (2019-nCoV) real-time rRT-PCR panel primers and probes. Retrieved April 19, 2020, from https://www.cdc.gov/coron avirus/2019-ncov/lab/rt-pcr-panel-primer-probes.html

Daughton, C. G., \& Jones-Lepp, T., L. (2001). Pharmaceuticals and personal care products in the environment: scientific and regulatory issues. Issue 791 of ACS symposium series, ISSN 0097-6156. American Chemical Society

Dong, L., Zhou, J., Niu, C., Wang, Q., Pan, Y., Sheng, S., Wang, X., Zhang, Y., Yang, J., Liu, M., \& Zhao, Y. (2021). Highly accurate and sensitive diagnostic detection of SARS-CoV-2 by digital PCR. Talanta, 224, 121726.

Falzone, L., Musso, N., Gattuso, G., Bongiorno, D., Palermo, C. I., Scalia, G., Libra, M., \& Stefani, S. (2020). Sensitivity assessment of droplet digital PCR for SARS-CoV-2 detection. International Journal of Molecular Medicine, 46(3), 957-964.

Graham, K., Loeb, S., Wolfe, M., Catoe, D., Sinnott-Armstrong, N., Kim, S., Yamahara, K., Sassoubre, L., Mendoza, L., RoldanHernandez, L., \& Li, L. (2020). SARS-CoV-2 in wastewater settled solids is associated with COVID-19 cases in a large urban sewershed. Environmental science \& technology, 55(1), 488-498.

Haramoto, E., Malla, B., Thakali, O., \& Kitajima, M. (2020). First environmental surveillance for the presence of SARS-CoV-2 RNA in wastewater and river water in Japan. Science of The Total Environment, $737,140405$.

Hart, O. E., \& Halden, R. U. (2020). Computational analysis of SARSCoV-2/COVID-19 surveillance by wastewater-based epidemiology locally and globally: Feasibility, economy, opportunities and challenges. Science of The Total Environment, 730, 138875.

He, K., Borthwick, A. G., Lin, Y., Li, Y., Fu, J., Wong, Y., \& Liu, W. (2020). Sale-based estimation of pharmaceutical concentrations and associated environmental risk in the Japanese wastewater system. Environment International, 139(1), 105690.

Hou, C., Hua, Z., Xu, P., Xu, H., Wang, Y., Liao, J., \& Di, B. (2020). Estimating the prevalence of hepatitis B by wastewater-based epidemiology in 19 cities in China. Science of The Total Environment, 740(1), 139696. 
Hovi, T., Shulman, L. M., Van Der Avoort, H., Deshpande, J., Roivainen, M., \& De Gourville, E. M. (2012). Role of environmental poliovirus surveillance in global polio eradication and beyond. Epidemiology \& Infection, 140(1), 1-13.

Huang, W. E., Lim, B., Hsu, C. C., Xiong, D., Wu, W., Yu, Y., Jia, H., Wang, Y., Zeng, Y., Ji, M., \& Chang, H. (2020). RT-LAMP for rapid diagnosis of coronavirus SARS-CoV-2. Microbial Biotechnology, 13(4), 950-961.

Hutinel, M., Huijbers, P. M. C., Fick, J., Åhrén, C., Larsson, D. G. J., \& Flach, C. F. (2019). Population-level surveillance of antibiotic resistance in Escherichia coli through sewage analysis. Eurosurveillance, 24(37), 1800497.

Jevtuševskaja, J., Krõlov, K., Tulp, I., \& Langel, Ü. (2017). The effect of main urine inhibitors on the activity of different DNA polymerases in loop-mediated isothermal amplification. Expert Review of Molecular Diagnostics, 17(4), 403-410.

Kumar, M., Patel, A. K., Shah, A. V., Raval, J., Rajpara, N., Joshi, M., \& Joshi, C. G. (2020). First proof of the capability of wastewater surveillance for COVID-19 in India through detection of genetic material of SARS-CoV-2. Science of the Total Environment, 746(1), 141326.

La Rosa, G., Iaconelli, M., Mancini, P., Ferraro, G. B., Veneri, C., Bonadonna, L., Lucentini, L., \& Suffredini, E. (2020). First detection of SARS-CoV-2 in untreated wastewaters in Italy. Science of the Total Environment, 736(1), 139652.

Lamb, L. E., Bartolone, S. N., Ward, E., \& Chancellor, M. B. (2020). Rapid detection of novel coronavirus (COVID19) by reverse transcription-loop-mediated isothermal amplification. Available at SSRN: https://ssrn.com/abstract=3539654 or http://dx.doi. org/10.2139/ssrn.3539654

Lee, S., Kim, T., Lee, E., Lee, C., Kim, H., Rhee, H., Park, S. Y., Son, H. J., Yu, S., Park, J. W., \& Choo, E. J. (2020). Clinical course and molecular viral shedding among asymptomatic and symptomatic patients with SARS-CoV-2 infection in a community treatment center in the Republic of Korea. JAMA Internal Medicine, 180(11), 1447-1452.

Li, W., Su, Y. Y., Zhi, S. S., Huang, J., Zhuang, C. L., Bai, W. Z., Wan, Y., Meng, X. R., Zhang, L., Zhou, Y. B., \& Luo, Y. Y. (2020). Virus shedding dynamics in asymptomatic and mildly symptomatic patients infected with SARS-CoV-2. Clinical Microbiology and Infection, 26(11), 1556-e1.

Liu, X., Feng, J., Zhang, Q., Guo, D., Zhang, L., Suo, T., Hu, W., Guo, M., Wang, X., Huang, Z., \& Xiong, Y. (2020). Analytical comparisons of SARS-COV-2 detection by qRT-PCR and ddPCR with multiple primer/probe sets. Emerging Microbes \& Infections, 9(1), 1175-1179.

Lodder, W., \& de Roda Husman, A. M. (2020). SARS-CoV-2 in wastewater: Potential health risk, but also data source. The Lancet. Gastroenterology and Hepatology, 1253(20), 30087.

Lu, R., Wang, J., Li, M., Wang, Y., Dong, J., \& Cai, W. (2020a). SARS-CoV-2 detection using digital PCR for COVID-19 diagnosis, treatment monitoring and criteria for discharge. Preprint (medRxiv). Available at https://www.medrxiv.org/content/10. $1101 / 2020.03 .24 .20042689 \mathrm{v} 1$

Lu, R., Wu, X., Wan, Z., Li, Y., Jin, X., \& Zhang, C. (2020b). A novel reverse transcription loop-mediated isothermal amplification method for rapid detection of SARS-CoV-2. International Journal of Molecular Sciences, 21(8), 2826.

Mao, K., Zhang, K., Du, W., Ali, W., Feng, X., \& Zhang, H. (2020). The potential of wastewater-based epidemiology as surveillance and early warning of infectious disease outbreaks. Current Opinion in Environmental Science and Health, 17, 1-7.

Medema, G., Heijnen, L., Elsinga, G., Italiaander, R., \& Brouwer, A. (2020). Presence of SARS-Coronavirus-2 RNA in sewage and correlation with reported COVID-19 prevalence in the early stage of the epidemic in the Netherlands. Environmental Science and Technology Letters, 7(7), 511-6.

Miyani, B., Fonoll, X., Norton, J., Mehrotra, A., \& Xagoraraki, I. (2020). SARS-CoV-2 in Detroit wastewater. Journal of Environmental Engineering, 146(11), 06020004.

Mukama, O., de Dieu Habimana, J., Meng, X., Ting, Y., Songwe, F., Al Farga, A., Mugisha, S., Rwibasira, P., Li, Z., \& Zeng, L. (2020). Synergetic performance of isothermal amplification techniques and lateral flow approach for nucleic acid diagnostics. Analytical Biochemistry, 600, 113762.

Nixon, G. J., Svenstrup, H. F., Donald, C. E., Carder, C., Stephenson, J. M., Morris-Jones, S., Huggett, J. F., \& Foy, C. A. (2014). A novel approach for evaluating the performance of real time quantitative loop-mediated isothermal amplification-based methods. Biomolecular Detection and Quantification, 2, 4-10.

Obande, G. A., \& Singh, K. K. B. (2020). Current and future perspectives on isothermal nucleic acid amplification technologies for diagnosing infections. Infection and Drug Resistance, 13, 455.

Park, G. S., Ku, K., Baek, S. H., Kim, S. J., Kim, S. I., Kim, B. T., \& Maeng, J. S. (2020). Development of reverse transcription loopmediated isothermal amplification (RT-LAMP) assays targeting SARS-CoV-2. The Journal of Molecular Diagnostics, 22(6), 729-735.

Randazzo, W., Truchado, P., Cuevas-Ferrando, E., Simón, P., Allende, A., \& Sánchez, G. (2020). SARS-CoV-2 RNA in wastewater anticipated COVID-19 occurrence in a low prevalence area. Water Research, 118(1), 115942.

Rimoldi, S. G., Stefani, F., Gigantiello, A., Polesello, S., Comandatore, F., Mileto, D., Maresca, M., Longobardi, C., Mancon, A., Romeri, F., Pagani, C., Cappelli, F., Roscioli, C., Moja, L., Gismondo, M. R., \& Salerno, F. (2020). Presence and infectivity of SARS-CoV-2 virus in wastewaters and rivers. Science of the Total Environment, 744(1), 140911.

Sherchan, S. P., Shahin, S., Ward, L. M., Tandukar, S., Aw, T. G., Schmitz, B., Ahmed, W., \& Kitajima, M. (2020). First detection of SARS-CoV-2 RNA in wastewater in North America: A study in Louisiana, USA. Science of The Total Environment, 743, 140621.

Sohn, Y., Jeong, S. J., Chung, W. S., Hyun, J. H., Baek, Y. J., Cho, Y., Kim, J. H., Ahn, J. Y., Choi, J. Y., \& Yeom, J. S. (2020). Assessing viral shedding and infectivity of asymptomatic or mildly symptomatic patients with COVID-19 in a later phase. Journal of Clinical Medicine, 9(9), 2924.

Tang, S., He, C., Thai, P. K., He, A., Vijayasarathy, S., Toms, L., Thompson, K., Hobson, P., Tscharke, B. J., Brien, J. W. O., Thomas, K. V., \& Mueller, J. F. (2020). Urinary concentrations of bisphenols in the Australian population and their association with the per capita mass loads in wastewater. Environmental Science and Technology, 54(16), 10141-10148.

Thekisoe, O. M., Bazie, R. S., Coronel-Servian, A. M., Sugimoto, C., Kawazu, S. I., \& Inoue, N. (2009). Stability of loop-mediated isothermal amplification (LAMP) reagents and its amplification efficiency on crude trypanosome DNA templates. Journal of Veterinary Medical Science, 71(4), 471-475.

Vasudevan, H. N., Xu, P., Servellita, V., Miller, S., Liu, L., Gopez, A., Chiu, C. Y., \& Abate, A. R. (2021). Digital droplet PCR accurately quantifies SARS-CoV-2 viral load from crude lysate without nucleic acid purification. Scientific Reports, 11(1), 1-9.

Wong, Y. P., Othman, S., Lau, Y. L., Radu, S., \& Chee, H. Y. (2018). Loop-mediated isothermal amplification (LAMP): A versatile technique for detection of micro-organisms. Journal of Applied Microbiology, 124(3), 626-643.

Wu, F., Xiao, A., Zhang, J., Gu, X., Lee, W. L., Kauffman, K., Hanage, W., Matus, M., Ghaeli, N., Endo, N., Duvallet, C., Moniz, K., Erickson, T., Chai, P., Thompson, \& Alm, E. (2020a). SARSCoV-2 titers in wastewater are higher than expected from clinically confirmed cases. Msystems, 5(4), e00614-20 
Wu, F., Zhang, J., Xiao, A., Gu, X., Lee, W. L., Armas, F., Kauffman, K., Hanage, W., Matus, M., Ghaeli, N., \& Endo, N. (2020b). SARS-CoV-2 titers in wastewater are higher than expected from clinically confirmed cases. Msystems. https://doi.org/10.1128/ mSystems.00614-20

Wurtzer, S., Marechal, V., Mouchel, J. M., \& Moulin, L. (2020). Time course quantitative detection of SARS-CoV-2 in Parisian wastewaters correlates with COVID-19 confirmed cases [Preprint]. Available at: https://doi.org/10.1101/2020.04.12.20062679

Yu, L., Wu, S., Hao, X., Dong, X., Mao, L., Pelechano, V., Chen, W. H., \& Yin, X. (2020). Rapid detection of COVID-19 coronavirus using a reverse transcriptional loop-mediated isothermal amplification (RT-LAMP) diagnostic platform. Clinical Chemistry, 66(7), 975-977.

Zuccato, E., Chiabrando, C., Castiglioni, S., Calamari, D., Bagnati, R., Schiarea, S., \& Fanelli, R. (2005). Cocaine in surface waters: A new evidence-based tool to monitor community drug abuse. Environmental Health, 4(1), 14-21.

Publisher's Note Springer Nature remains neutral with regard to jurisdictional claims in published maps and institutional affiliations. 